\title{
The potential of volatile organic compound analysis in cervicovaginal mucus to predict estrus and ovulation in estrus-synchronized heifers
}

\author{
Katarzyna Pluta, ${ }^{1} \oplus$ Peter R. H. Jones, ${ }^{2} \odot$ Natalia Drabińska, ${ }^{3,4} \oplus$ Norman Ratcliffe, ${ }^{3}$ Stephen D. Carrington, ${ }^{1} \odot$ \\ Patrick Lonergan, ${ }^{5}$ (1) and Alexander C. O. Evans ${ }^{5 *}$ () \\ ${ }^{1}$ School of Veterinary Medicine, University College Dublin, Belfield, Dublin 4, Ireland \\ ${ }^{2}$ Indigo Science Ltd., Ashley Down, Bristol, BS7 9JS, United Kingdom \\ ${ }^{3}$ Institute of Biosensor Technology, University of the West of England, Coldharbour Lane, Frenchay, Bristol, BS16 1QY, United Kingdom \\ ${ }^{4}$ Institute of Animal Reproduction and Food Research of Polish Academy of Sciences, 10 Tuwima Str., 10-748 Olsztyn, Poland \\ ${ }^{5}$ School of Agriculture and Food Science, University College Dublin, Belfield, Dublin 4, Ireland
}

\begin{abstract}
Cervicovaginal mucus is a mixture of mucins, ions, salts, and water, the proportions of which change during the reproductive cycle. It is suspected that this mucus emits an important volatile signal indicative of the reproductive state of the female. The objective of this study was to identify volatile organic compounds (VOC) in bovine cervicovaginal mucus that are modulated during the estrous cycle and could potentially be used as biomarkers of estrus and ovulation. Cervicovaginal mucus was collected from crossbred beef heifers $(\mathrm{n}=8)$, which were synchronized using an 8-d controlled internal drug release (CIDR) protocol and in which onset of estrus and time of ovulation were determined by visual observation and ultrasonography, respectively. Mucus samples were collected between 0 and $96 \mathrm{~h}$ after CIDR removal (estrus onset occurred at $49.1 \pm 3.3 \mathrm{~h}$ after CIDR removal). A validation study was performed on an independent group of 15 heifers from which cervicovaginal mucus samples were collected every $8 \mathrm{~h}$ from 40 to $80 \mathrm{~h}$ after CIDR removal. The VOC in mucus were identified using gas chromatography-mass spectrometry and selected compounds were quantified using selected-ion flow-tube mass spectrometry. The presence of $47 \mathrm{VOC}$ was detected in mucus samples by gas chromatography-mass spectrometry with those exhibiting highest abundance including 2-butanone, acetone, 2-pentanone, 4-methyl2-pentanone, 1-(1-methylethoxy)-2-propanone, ethanol, 2-methyl-2-propanol, and 2-butanol. All VOC peaked between 24 to $47 \mathrm{~h}$ after the onset of estrus (ovulation occurred $26.6 \pm 5.6 \mathrm{~h}$ after estrus onset). Two VOC, 2-pentanone and 4-methyl-2-pentanone, exhibited
\end{abstract}

Received June 4, 2020.

Accepted September 1, 2020.

*Corresponding author: alex.evans@ucd.ie a significant increase at the onset of estrus, whereas concentration of 2-butanone increased significantly just after estrus onset, indicating that these VOC may be used as putative biomarkers of estrus. The results of our study may contribute to the development of a sensor device based on VOC to aid the detection of estrus and ovulation in cattle, with particular relevance for the dairy industry where the majority of females are bred by artificial insemination.

Key words: biomarkers, bovine, mass spectrometry, gas chromatography, selected-ion flow-tube mass spectrometry

\section{INTRODUCTION}

Reproductive efficiency is a major driver of profitability in livestock production systems (Cabrera, 2014), particularly in seasonal systems (Shalloo et al., 2014). The 2 main drivers of reproductive efficiency in dairy operations are submission rate - the proportion of eligible cows presented for breeding, and conception rate - the proportion of cows becoming pregnant to a given insemination. In seasonal pasture-based dairy production systems, a compact calving pattern relies heavily on achieving high submission rates in the first $21 \mathrm{~d}$ of the breeding season.

Detection of the time of ovulation is challenging, requiring repeated transrectal ultrasonography. However, this is labor intensive, requires specific skills, and may be impractical at farm level. In the absence of timed AI protocols, which are used infrequently in many countries, accurate detection of the onset of estrus, which occurs approximately $28 \mathrm{~h}$ before ovulation (Walker et al., 1996; Valenza et al., 2012; Randi et al., 2018), is critical to ensure AI is carried out at the appropriate time. This is even more important when sex-sorted semen is used, given the lower concentration of sperm per dose and apparent shorter sperm lifespan (Bombardelli et al., 2016; Nebel, 2018). On farms, estrus is typically 
detected based on visual observation of well characterized behaviors including standing to be mounted by herdmates, increased activity, swelling of the vulva, and a clear mucus discharge, often with the aid of tail paint, mount-detecting patches, or a vasectomized bull (Larson and Ball, 1992). However, visual detection of estrus is a demanding activity and is affected by numerous factors including days postpartum, number of lactations, milk yield, lameness, nutrition, size of the sexually active group, and the under-foot surface characteristics (Roelofs et al., 2010). More sophisticated approaches include the use of electronic devices that detect mounting activity (Walker et al., 1996; Valenza et al., 2012) or the increase in activity associated with estrus (Fricke et al., 2014; Burnett et al., 2018). However, the duration of estrus is often very limited (Dobson et al., 2018); in one study in lactating dairy cows, mean estrus period, determined from mounting activity recorded using the Heatwatch system, consisted of 10.1 mounts over $9.5 \mathrm{~h}$ for a total $24.1 \mathrm{~s}$ of mounting activity (Walker et al., 1996), illustrating the challenge in capturing this very narrow window of time by visual observation alone. Failure to detect estrus has significant financial implications due to insemination and veterinary costs, and the consequences of extended calving intervals (Roelofs et al., 2010; Veronese et al., 2019).

The Flehmen response, exhibited by a wide range of mammals, including ungulates, facilitates the transfer of pheromones and other volatile olfactory cues to the vomeronasal organ (or Jacobson's organ). Bulls exhibit this behavior in response to the presence of a mixture of volatile pheromones present in female excretions (Sankar and Archunan, 2004). Not only mucus but also urine and feces can be a source of volatile organic compounds (VOC) associated with estrus (Le Danvic et al., 2015; Mozūraitis et al., 2017; Ramachandran et al., 2020). It has been reported that acetic acid, propionic acid, and 1-iodoundecane are present in bovine feces specifically at estrus, and application to the genital region of diestrous cows stimulated mounting behavior and the Flehmen response in bulls (Sankar and Archunan, 2004). Changes in acetic and propionic acid in feces relative to the time of ovulation have also been described (Mozūraitis et al., 2017). Interestingly, animals with a highly developed olfactory system are also able to detect estrus in cows. For example, specially trained dogs were able to detect cows in estrus based on odors originating from vaginal swabs (Kiddy et al., 1978), milk (Hawk et al., 1984), and urine (Kiddy et al., 1984; Fischer-Tenhagen et al., 2015). Similarly, trained rats (Dehnhard and Claus, 1988) and mice (Sankar and Archunan, 2005) exposed to bovine urine could distinguish between estrous and diestrous animals. Indeed, certain hematophagous arthropods can discriminate stages of the mammalian reproductive cycle based on host volatiles; for example, female face flies (Musca autumnalis) could discriminate between urine from cows in estrus and urine collected during the luteal phase (Nordéus et al., 2014).

Despite these studies, the profile of VOC in vaginal and cervical secretion and their cyclical changes have not been fully elucidated. An understanding of the volatile signals associated with estrus and ovulation will improve our ability to noninvasively monitor reproductive activity and help in understanding the intricacies of bovine reproductive behavior. Moreover, this information will contribute to the development of sensor devices based on the specific VOC, characteristic for estrus and ovulation, that may reduce the costs and increase the efficiency of animal husbandry. Hence, the objective of this study was to determine changes in the VOC signature of bovine cervicovaginal mucus during estrus and ovulation using the latest technologies including GC-MS and selected-ion flow-tube (SIFT) MS.

\section{MATERIALS AND METHODS}

This study was approved by the University College Dublin Animal Research Ethics Committee. All experimental procedures involving animals were licensed by the Department of Health and Children, Ireland according to the Cruelty to Animals Act (Ireland 1897) and European Community Directive 86/609/ EC (Louhimies, 2002). The study consisted of 2 experiments; experiment 1 was conducted to identify VOC in cervicovaginal mucus and experiment 2 was conducted to validate the most promising findings of experiment 1.

\section{Experiment 1-VOC Profiling in Cervicovaginal Mucus}

Estrus was synchronized in nulliparous crossbred beef heifers $(\mathrm{n}=14$, approximately $24 \mathrm{mo}$ and $580 \mathrm{~kg})$ by insertion of a controlled internal drug release (CIDR) device (1.94 g of progesterone; Pfizer Animal Health, Groton, CT) into the vagina for 8 d. A $0.5-\mathrm{mg}$ i.m. injection of $\mathrm{PGF}_{2 \alpha}$ analog (Estrumate, Schering-Plough Animal Health, Hertfordshire, UK) was administered 1 $\mathrm{d}$ before CIDR removal. Heifers were checked for standing estrus between 24 and $60 \mathrm{~h}$ after CIDR withdrawal, by visual observation by trained personnel every $4 \mathrm{~h}$. Onset of estrus was defined as the time a heifer first stood to be mounted by a herdmate. Only those heifers producing sufficient volumes of mucus samples (see below) and exhibiting estrus by $60 \mathrm{~h}$ after CIDR withdrawal were used $(\mathrm{n}=8)$. 

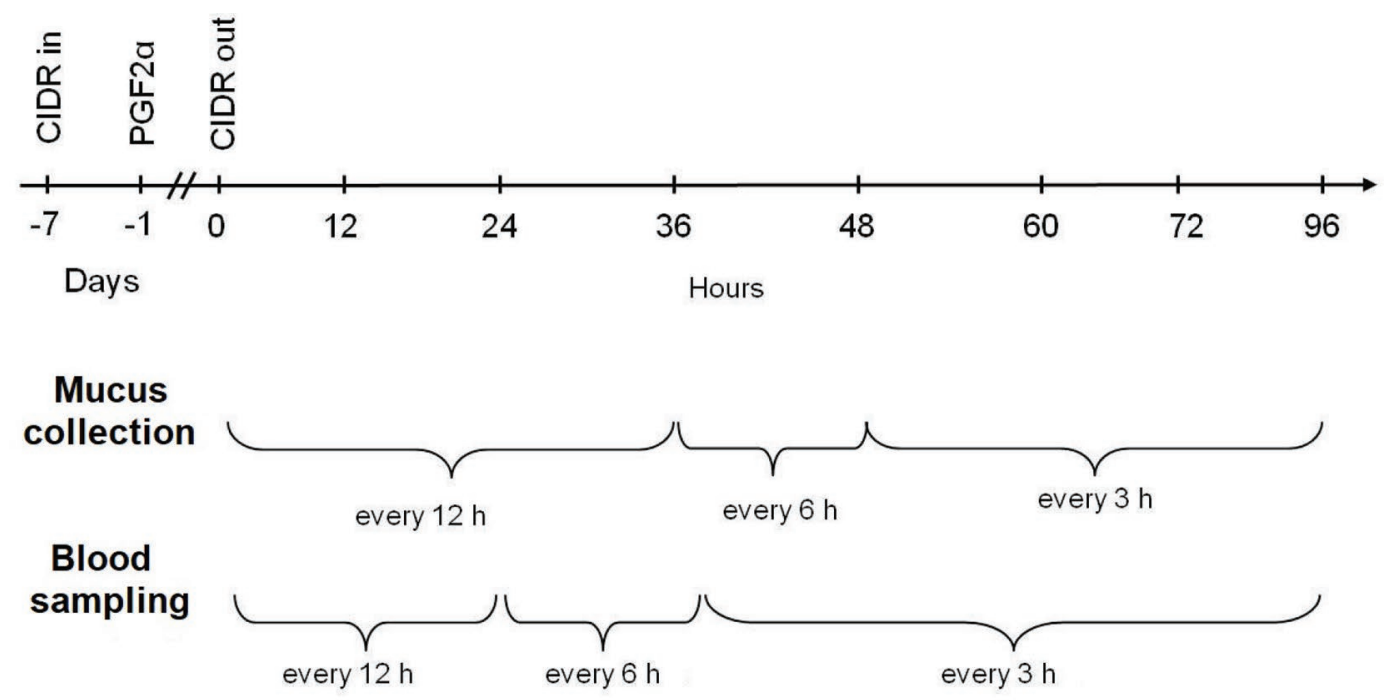

Estrus check

Ultrasound

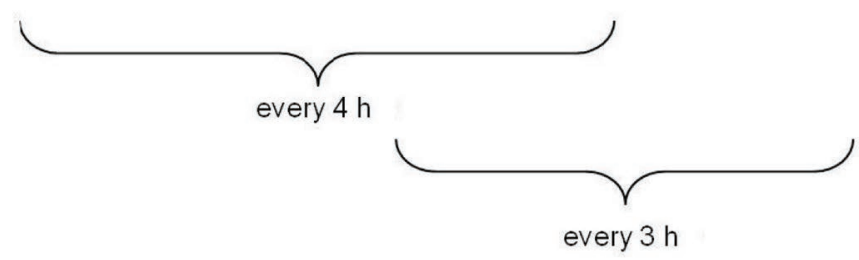

Figure 1. Design of experiment 1, including estrous synchronization plan, frequency of mucus collection, blood sampling, estrus checking, and ultrasound examination. CIDR $=$ controlled internal drug release device.

After CIDR removal, blood samples were collected by jugular venipuncture according to the following schedule: every 12 to $24 \mathrm{~h}$ after CIDR removal, every $6 \mathrm{~h}$ from 24 to $36 \mathrm{~h}$, and every $3 \mathrm{~h}$ from 36 to $96 \mathrm{~h}$ after CIDR removal (Figure 1). Serum samples were prepared within $12 \mathrm{~h}$ of sampling, aliquoted, and stored at $-20^{\circ} \mathrm{C}$ before assaying concentrations of $\mathrm{LH}$ and estradiol according to the previously described protocols (Cooke et al., 1997; Forde et al., 2009).

The time of ovulation was assessed using transrectal ultrasonography that was conducted every $3 \mathrm{~h}$ from 48 to $96 \mathrm{~h}$ after CIDR removal (Figure 1). Ovulation was deemed to have occurred at the mid-point between the last ultrasound scanning when a large preovulatory follicle was present and the first scan when it was absent.

Each heifer was subjected to mucus sampling 22 times. Mucus samples were collected every $12 \mathrm{~h}$ from CIDR removal to $36 \mathrm{~h}$, every $6 \mathrm{~h}$ between 36 and $48 \mathrm{~h}$, and every $3 \mathrm{~h}$ between 48 and $96 \mathrm{~h}$, as presented in Figure 1. Samples were collected from the anterior vagina using a 53.5-cm bovine uterine catheter (Acravet, Mallow, Co. Cork, Ireland). Sampling was carried out by palpating the cervix per rectum and then inserting a catheter through the vagina toward the external cervical os. To eliminate contamination of the mucus sample, catheters were covered with a plastic sleeve during insertion and the tip of the catheter was protruded from the sleeve once it had reached the anterior vagina and the cervix. To collect the sample, a $50-\mathrm{mL}$ syringe was placed at the end of the catheter and suction was applied. Within $1 \mathrm{~h}$ of collection, 1-g samples were aliquoted into $10-\mathrm{mL}$ septum-topped headspace vials (Supelco, Bellefonte, PA) and then stored at $-20^{\circ} \mathrm{C}$ until further analysis.

\section{Experiment 2}

Experiment 2 was conducted to confirm the findings of experiment 1. Twenty-four nulliparous crossbred beef heifers were synchronized using a CIDR and $\mathrm{PGF}_{2 \alpha}$ as described in experiment 1. Animals were observed for signs of estrus every $4 \mathrm{~h}$ from 24 to $60 \mathrm{~h}$ after CIDR removal. The first 15 heifers exhibiting estrus were used for mucus sampling $(\mathrm{n}=15)$. Mucus samples were collected every $8 \mathrm{~h}$ from 40 to $80 \mathrm{~h}$ after CIDR removal (Figure 2) as described in experiment 1 above.

\section{VOC Analysis}

One gram of each mucus sample was placed in 20$\mathrm{mL}$ headspace vials and equilibrated at $60^{\circ} \mathrm{C}$ for 30 
min on a heating block to allow VOC to diffuse into the headspace. The VOC were then collected by static headspace extraction, for $20 \mathrm{~min}$, using conditioned $85-\mu \mathrm{m}$ carboxen/polydimethylsiloxane, StableFlex SPME fibers (Supelco), which were then transferred immediately to the gas chromatograph injection port for desorption at $220^{\circ} \mathrm{C}$ with the split valve closed (Abuelnnor et al., 2010).

The GC-MS analyses were performed using a Perkin Elmer Clarus 500 GC-MS (Perkin Elmer, Waltham, MA) quadrupole benchtop system fitted with a 1-mm quartz liner. The analytical column was a ZB-624 fused-silica capillary column, $60 \mathrm{~m} \times 0.25 \mathrm{~mm}$ i.d. $\times$ $1.40 \mu \mathrm{m}$ film thickness (Phenomenex, Macclesfield, UK). The carrier gas was $99.9995 \%$ pure helium (BOC, Guilford, UK), and was passed through an Excelasorb helium purification system (Sigma-Aldrich Ltd., Dorset, UK) at $1.3 \mathrm{~mL} \cdot \mathrm{min}^{-1}$. The $\mathrm{GC}$ was operated under the following conditions: temperature program $40^{\circ} \mathrm{C}$ (1 min initial hold), a ramp of $5^{\circ} \mathrm{C} \min ^{-1}$ to $220^{\circ} \mathrm{C}$, and then held at $220^{\circ} \mathrm{C}$ for $4 \mathrm{~min}$, giving a total run time of $41 \mathrm{~min}$. The ion source and the transfer line temperatures were $180^{\circ} \mathrm{C}$ and $280^{\circ} \mathrm{C}$, respectively. The mass spectrometer was operated in electron ionization mode scanning from mass charge ratio 10 to 300 (2-41 min), scan time $0.25 \mathrm{~s}$, and interscan delay $0.05 \mathrm{~s}$. Total ion chromatograms were analyzed with the Turbomass software (Perkin Elmer) and compounds are expressed as the area under the curve. The identification of the VOC was performed by comparison of the mass spectra with the NIST/EPA/NIH Mass Spectral Library (version 2.2, 2014; https://www.nist.gov/system/files/ documents/srd/NIST1aVer22Man.pdf) and by comparing retention times and calculating linear retention indices relative to a series of alkanes (C6-C30), according to Zellner et al. (2008). Although retention times vary with the individual chromatographic system (e.g., with regard to column length, film thickness, diameter, and inlet pressure), the derived retention indices are independent of these variables and allow comparison of values measured under varying conditions. Tables of retention indices, separate for the different column types, are used to identify peaks by comparing measured retention indices with the tabulated values. The wide range of alkanes applied allows for the identification of all the compounds between them.

Samples in experiment 1 were also analyzed using SIFT-MS (Trans Spectra, Newcastle Under-Lyme, Staffordshire, UK). The SIFT-MS uses ultra-soft, precisely controlled chemical ionization coupled with MS detection that allows for rapid quantification of VOC and permanent gases to low parts-per-trillion concentrations by volume. Therefore, SIFT-MS was used to quantify VOC of interest identified using the GC-MS method (2-butanone). Moreover, acetaldehyde and lactic acid, which cannot readily be detected by GC-MS, and were previously reported in the literature as being associated with estrous cycles (Preti and Huggins, 1975; Klemm et al., 1994) were also measured using SIFT-MS. Compounds present in the headspace above the mucus samples were analyzed directly using the SIFT-MS and measured according to masses of compounds of interest (Table 1).

\section{Data Analyses}

All data were aligned to the time of estrus onset $(0 \mathrm{~h})$ with the hormone data considered in 3-h intervals and

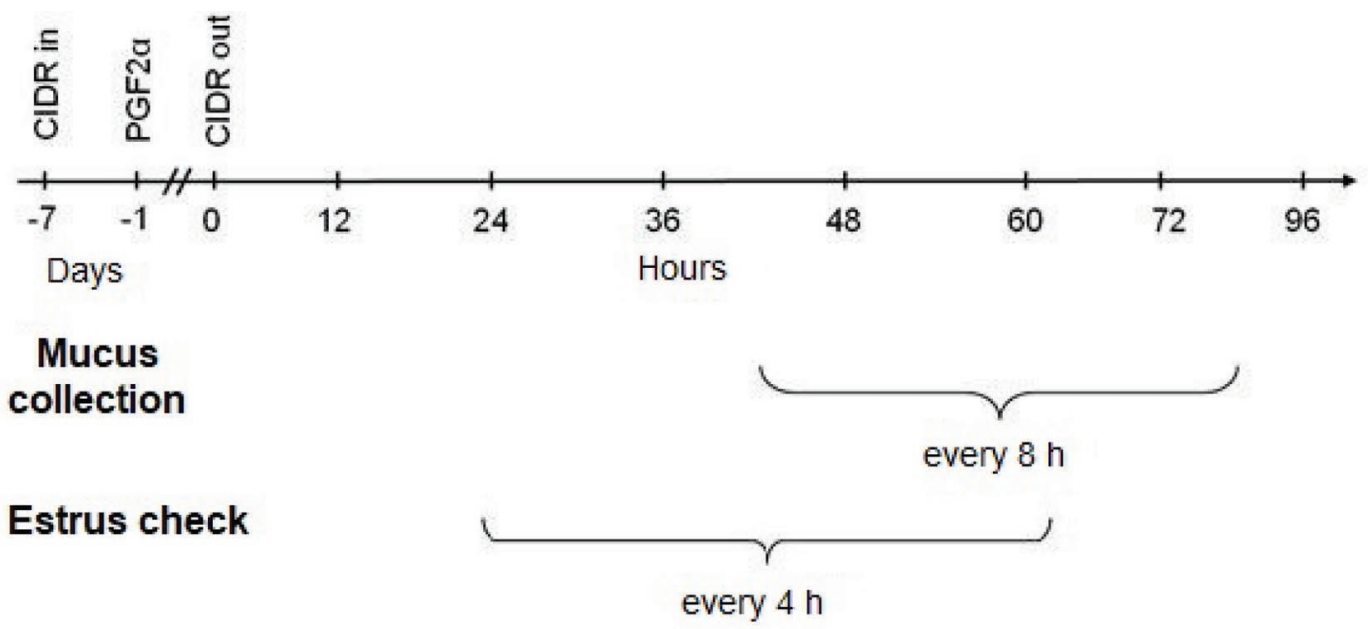

Figure 2. Design of experiment 2, including estrous synchronization plan, frequency of mucus collection, and estrus checking. CIDR $=$ controlled internal drug release device. 

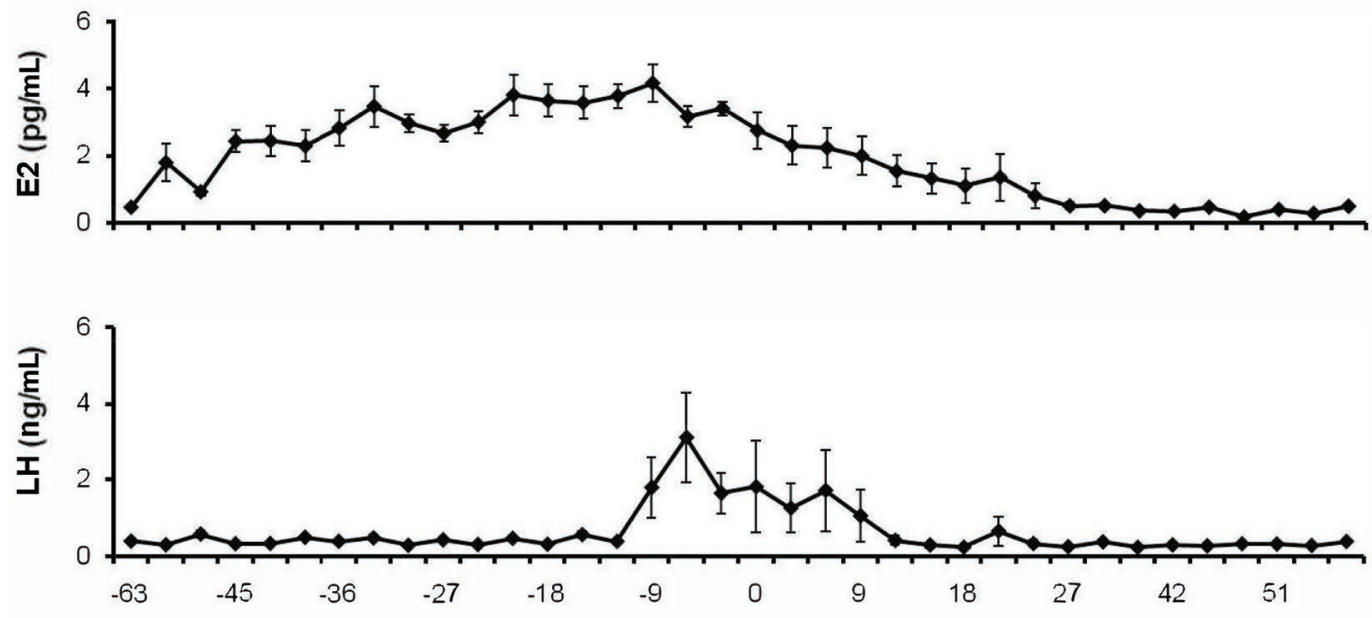

Hours from the onset of estrus

Figure 3. Mean $( \pm$ SEM) serum concentrations of estradiol $(\mathrm{E} 2)$ and LH in synchronized beef heifers $(\mathrm{n}=8)$. Blood samples were collected by jugular venipuncture every 12 to $24 \mathrm{~h}$ after controlled internal drug release device (CIDR) removal, every $6 \mathrm{~h}$ from 24 to $36 \mathrm{~h}$, and every $3 \mathrm{~h}$ from 36 to $96 \mathrm{~h}$ after CIDR removal and aligned to the onset of estrus (h 0). Ovulation occurred $26.6 \pm 5.6 \mathrm{~h}$ after the onset of estrus.

the VOC data considered in 12-h intervals. Data were compared among time points using a repeated measures model (PROC MIXED, SAS 9.1, SAS Institute Inc., Cary, NC), assuming a compound symmetry correlation structure. To stabilize the variability of the VOC data, the peak areas were subjected to logarithmic transformations. Differences between time points were considered as significant when $P<0.05$. All data are presented as the mean \pm standard error of the mean.

\section{RESULTS}

\section{Experiment 1}

Analysis of serum estradiol and LH concentrations confirmed that the animals $(n=8)$ responded to the hormonal synchronization. Estradiol concentrations started to increase from the time of CIDR removal (first blood sample taken) to a peak of $4.2 \mathrm{pg} / \mathrm{mL}, 9$ $\mathrm{h}$ before the onset of estrus (Figure 3). The highest average LH concentration was observed $6 \mathrm{~h}$ before the onset of estrus (Figure 3). The onset of estrus occurred $49.1 \pm 3.3 \mathrm{~h}$ after CIDR removal, whereas ovulation occurred $26.6 \pm 5.6 \mathrm{~h}$ after the onset of estrus.

Due to the complexity of the mucus sampling process and interanimal variation, different numbers and quantities of samples were obtained per heifer. On average, $15 \pm 4$ (mean $\pm \mathrm{SD}$ ) usable samples were collected per animal. Insufficient volumes of mucus to allow VOC measurement either by GC-MS or SIFT-MS were recovered at time points up to $35 \mathrm{~h}$ before estrus onset and from $60 \mathrm{~h}$ after estrus onset. All samples were subjected to SIFT-MS analysis $(\mathrm{n}=8$ heifers $)$ and a reduced number of samples was subjected to GC-MS

Table 1. Masses of ions present in compounds of interest (acetaldehyde, 2-butanone, and lactic acid) assayed using selected-ion flow-tube MS in experiment 1

\begin{tabular}{llcl}
\hline Compound & Ion & Mass $(\mathrm{Da})$ & Formula \\
\hline Acetaldehyde & $\mathrm{NO}^{+}$ & 43 & $\mathrm{CH}_{3} \mathrm{CO}^{+}$ \\
& $\mathrm{NO}^{+}$ & 61 & $\mathrm{CH}_{3} \mathrm{CO}^{+} \cdot \mathrm{H}_{2} \mathrm{O}$ \\
& $\mathrm{NO}^{+}$ & 79 & $\mathrm{CH}_{3} \mathrm{CO}^{+} \cdot 2 \mathrm{H}_{2} \mathrm{O}$ \\
2-Butanone & $\mathrm{O}_{2}^{+}$ & 44 & $\mathrm{C}_{2} \mathrm{H}_{4} \mathrm{O}^{+}$ \\
& $\mathrm{NO}^{+}$ & 102 & $\mathrm{C}_{4} \mathrm{H}_{8} \mathrm{O}^{+} \mathrm{NO}^{+}$ \\
Lactic acid & $\mathrm{O}_{2}^{+}$ & 77 & $\mathrm{C}_{3} \mathrm{H}_{5} \mathrm{O}^{+}$ \\
& $\mathrm{O}_{2}^{+}$ & 72 & $\mathrm{C}_{4} \mathrm{H}_{8} \mathrm{O}^{+}$ \\
& $\mathrm{NO}^{+}$ & 120 & $\mathrm{CH}_{3} \mathrm{CH}(\mathrm{OH}) \mathrm{CO}^{+}$ \\
& $\mathrm{NO}^{+}$ & 45 & $\mathrm{CH}_{3} \mathrm{CH}(\mathrm{OH}) \mathrm{COOH}^{+} \mathrm{NO}^{+}$ \\
& $\mathrm{O}_{2}^{+}$ & 63 & $\mathrm{CH}_{3} \mathrm{CHOH}^{+}$ \\
& $\mathrm{O}_{2}{ }^{+}$ & 81 & $\mathrm{CH}_{3} \mathrm{CHOH}^{+} \cdot \mathrm{H}_{2} \mathrm{O}$ \\
\hline
\end{tabular}


analysis due to insufficient sample quantity ( 8 to 12 samples from each of 5 animals).

The cervicovaginal mucus was found to be a rich source of VOC, containing 47 individual compounds detected with GC-MS, as presented in Table 2. Of the compounds detected, those exhibiting greatest variation in abundance were the ketones: acetone, 2-butanone, 2-pentanone, 4-methyl-2-pentanone, and 1-(1-methylethoxy)-2 propanone (Figure 4$)$. The concentration of 2-butanone was basal from $36 \mathrm{~h}$ before to $11 \mathrm{~h}$ after estrus onset and then increased $(P<0.05)$ to peak between 36 and $47 \mathrm{~h}$ after estrus onset, reaching a much larger order of magnitude $\left(10^{9}\right.$ vs. $\left.\sim 10^{6}\right)$ than the other compounds, after which it decreased (Figure $4 \mathrm{~b})$. Acetone had the lowest abundance between 36 and $25 \mathrm{~h}$ before estrus and exhibited a significant increase between 12 and $1 \mathrm{~h}$ before estrus, and a further steady significant increase between 36 and $47 \mathrm{~h}$ after estrus onset (Figure 4a). The abundance of both 2-pentanone and 4-methyl-2-pentanone decreased before estrus, reaching a nadir between 12 and $1 \mathrm{~h}$ before estrus (Figure $4 \mathrm{c}$ and $4 \mathrm{~d})$. At the onset of estrus, the abundance of these compounds increased and peaked between 24 and $35 \mathrm{~h}$ after estrus onset. The 1-(1-methylethoxy)2 -propanone had the lowest concentration between 36 and $25 \mathrm{~h}$ before estrus and increased subsequently, reaching the highest value between 36 and $47 \mathrm{~h}$ after estrus (Figure 4e).

In addition to ketones, the abundance of 3 alcohols, ethanol, 2-methyl-2-propanol and 2-butanol, varied across the experimental time course (Figure 5). Concentrations of 2-butanol were very low from $36 \mathrm{~h}$ before estrus to the onset of estrus and then increased consid- erably (Figure 5c). Ethanol and 2-methyl-2-propanol exhibited a similar pattern during the period about estrus (Figure 5a and 5b). All 3 alcohols exhibited greatest abundance between 36 and $47 \mathrm{~h}$ after estrus (Figure 5).

Concentrations of 2-butanone along with acetaldehyde and lactic acid were assessed by SIFT-MS using samples from 8 heifers. The abundance of 2-butanone was the highest; therefore, this VOC was used to validate results from GC-MS. The abundance of acetaldehyde was greatest between 24 and $47 \mathrm{~h}$ after estrus and differed significantly from all other time points $(P<$ 0.001; Figure 6a). The abundance of lactic acid was very low before estrus and until $23 \mathrm{~h}$ after the onset of estrus and then increased dramatically between 24 and $35 \mathrm{~h}$ after estrus, subsequently decreasing. Similarly to results obtained by GC-MS, 2-butanone exhibited a low concentration until $11 \mathrm{~h}$ after the onset of estrus, following which its abundance increased. The highest concentration was observed between 24 and $35 \mathrm{~h}$ after estrus, one time point earlier than by when measured by GC-MS. However, the values between 24 and $47 \mathrm{~h}$ after estrus in both analyses did not differ. Considering the average of the individual animal profiles, the peak abundance of acetaldehyde, lactic acid, and 2-butanone occurred 30.6, 25.2, and $32.3 \mathrm{~h}$ after the onset of estrus, respectively.

\section{Experiment 2}

As 2-butanone exhibited the greatest temporal changes (low baseline to a high peak) in both relative abundance measured by GC-MS (Figure 4) and concen-

Table 2. Volatile organic compounds detected in bovine cervicovaginal mucus using GC-MS

\begin{tabular}{|c|c|c|c|}
\hline Alcohols & Alkanes & Ketones & Aldehydes \\
\hline
\end{tabular}



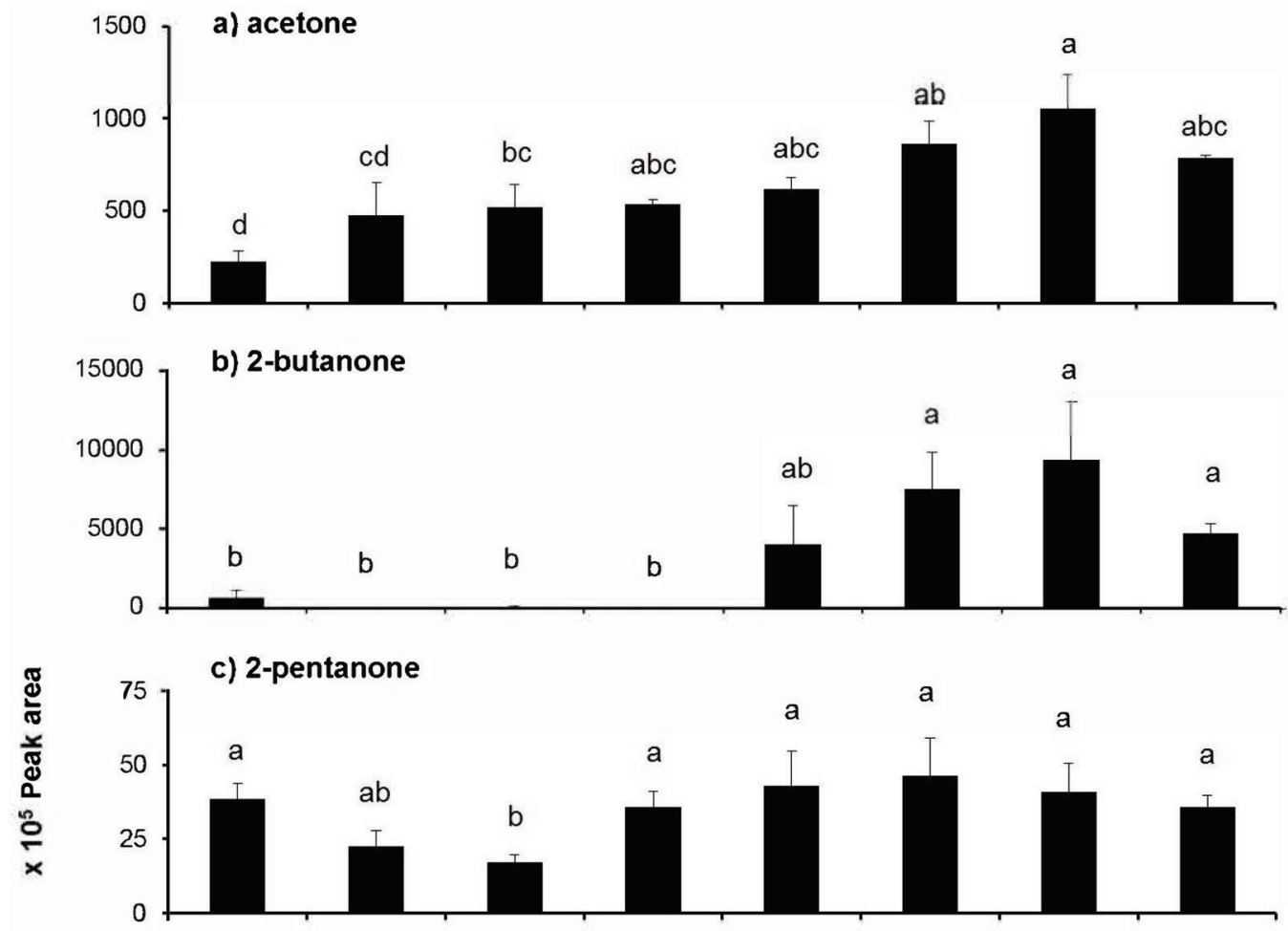

d) 4-methyl-2-pentanone
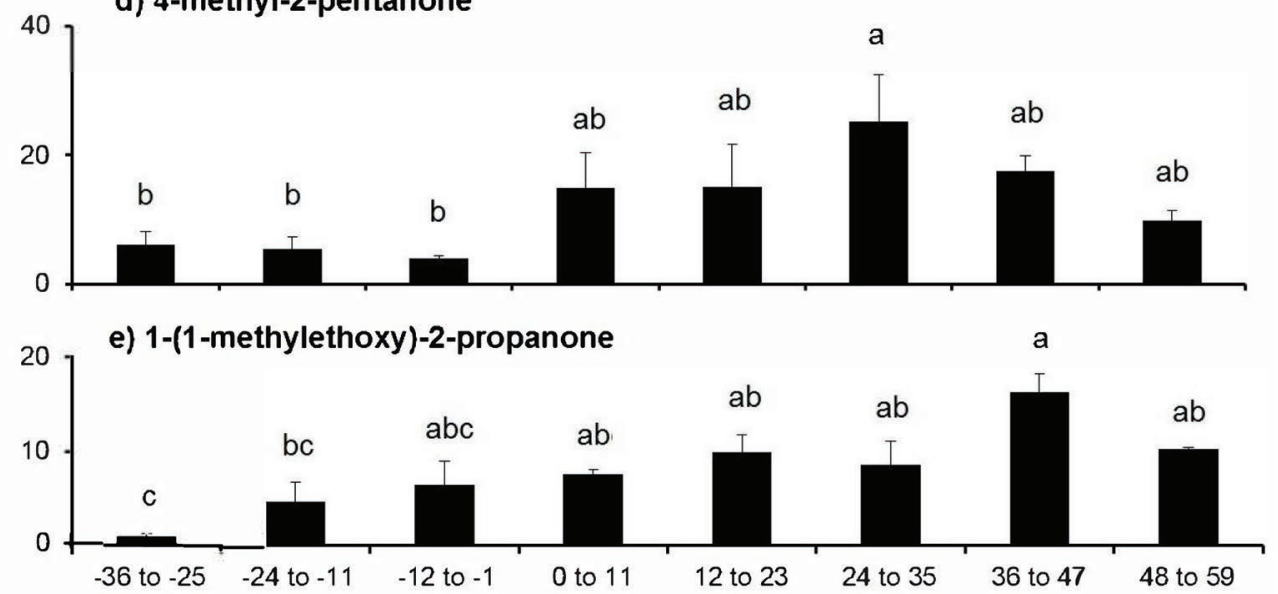

Hours from the onset of estrus

Figure 4. Mean $( \pm$ SEM) relative abundance (peak area) of ketones in cervicovaginal mucus of heifers in experiment $1(\mathrm{n}=5)$ measured by GC-MS, presented in 12-h blocks of time relative to the onset of estrus (h 0 ). Compounds are listed according to the size of the molecule: (a) acetone, (b) 2-butanone, (c) 2-pentanone, (d) 4-methyl-2-pentanone, and (e) 1-(1-methylethoxy)-2-propanone. Columns without a common letter $(\mathrm{a}-\mathrm{d})$ are different $(P<0.05)$.

tration measured by SIFT-MS (Figure 6), it was also measured in the samples collected in experiment 2 by GC-MS $(\mathrm{n}=15)$. The onset of estrus was $34.9 \pm 1.5 \mathrm{~h}$ after CIDR removal. 2-Butanone abundance increased in postestrus mucus with the greatest abundance occurring $71.8 \pm 3.6 \mathrm{~h}$ after CIDR removal and $36.9 \pm 3.0$ $\mathrm{h}$ after the onset of estrus (Figure 7 ).

\section{DISCUSSION}

Appropriate timing of AI is critical to ensure fertilization of the oocyte soon after ovulation (Diskin, 2018). In many scenarios, the timing of ovulation is precisely controlled using pharmaceutical protocols allowing timed insemination (Carvalho et al., 2018). 


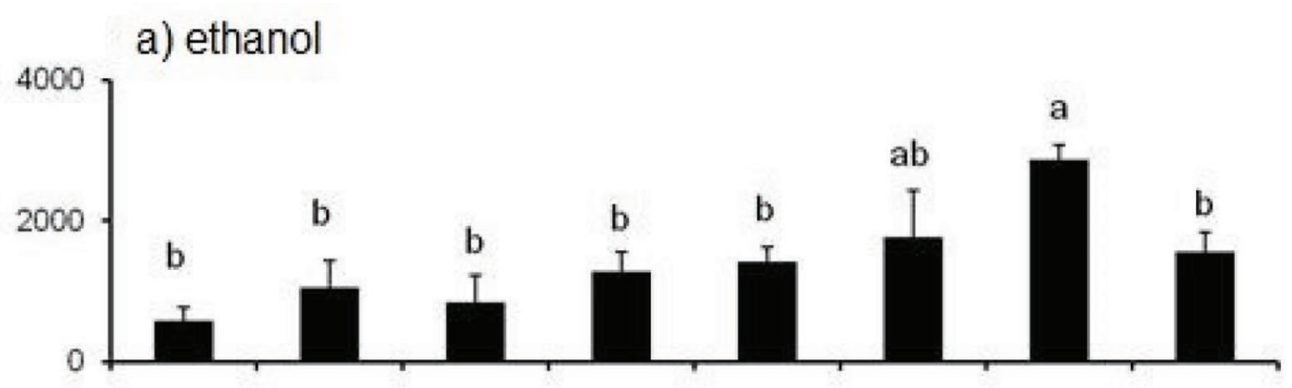

b) 2-methyl-2-propanol

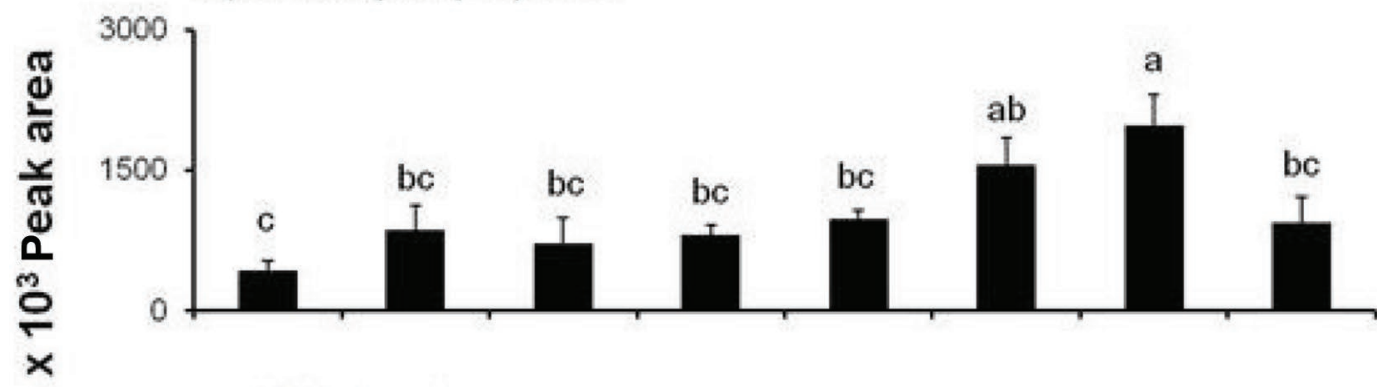

c) 2-butanol

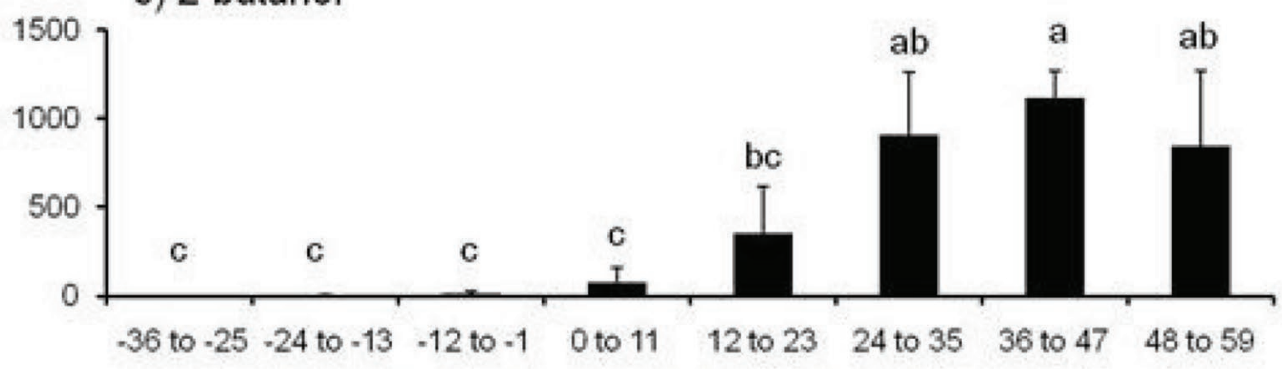

Hours from the onset of estrus

Figure 5. Mean $( \pm$ SEM) relative abundance (peak area) of alcohols in cervicovaginal mucus of heifers $(\mathrm{n}=5)$ in experiment 1 , measured by GC-MS, presented in 12-h blocks of time relative to the onset of estrus (h 0). Compounds are listed according to the size of the molecule: (a) ethanol, (b) 2-methyl-2-propanol, and (c) 2-butanol. Columns without a common letter (a-c) are different $(P<0.05)$.

In the absence of such protocols, timing of ovulation is estimated by the time of estrus onset, requiring the latter to be precisely determined. In this study, we characterized the temporal dynamics in the profile of VOC in bovine cervicovaginal mucus about the time of estrus and ovulation with some VOC exhibiting greater and more distinct temporal changes than others. To the best of our knowledge, this study identified the highest number (47) of VOC in cervicovaginal mucus to date. Despite the large variation in mucus quantities and interanimal variation, a similar pattern was observed in all heifers. Most of the major compounds were detected at low concentrations from $36 \mathrm{~h}$ before the onset of estrus and then increased after the onset of estrus to reach the maximum values between 36 to $47 \mathrm{~h}$ later about the time of ovulation. The compounds identified in highest concentrations were mostly ketones [2-butanone, 2-pentanone, 4-methyl2-pentanone, 1-(1-methylethoxy)-2-propanone, acetone], and alcohols (ethanol, 2-methyl-2-propanol, and 2-butanol).

Most of the abundant compounds reported here exhibited significant increases after the onset of estrus, with peak concentrations occurring closer to the time of ovulation (well after estrus) than to the time of the onset of estrus. However, 2 compounds (2-pentanone and 2-methyl-2-pentanone) did exhibit significant increases at the time of the onset of estrus, suggesting that they may be important in signaling the onset of estrus to other animals. 2-Pentanone is an interesting compound because its concentration increased at the time of estrus and remained at a similar level in the postestrus period. The source of 2-pentanone remains unknown but it is assumed to be a product of fatty 
a) acetaldehyde
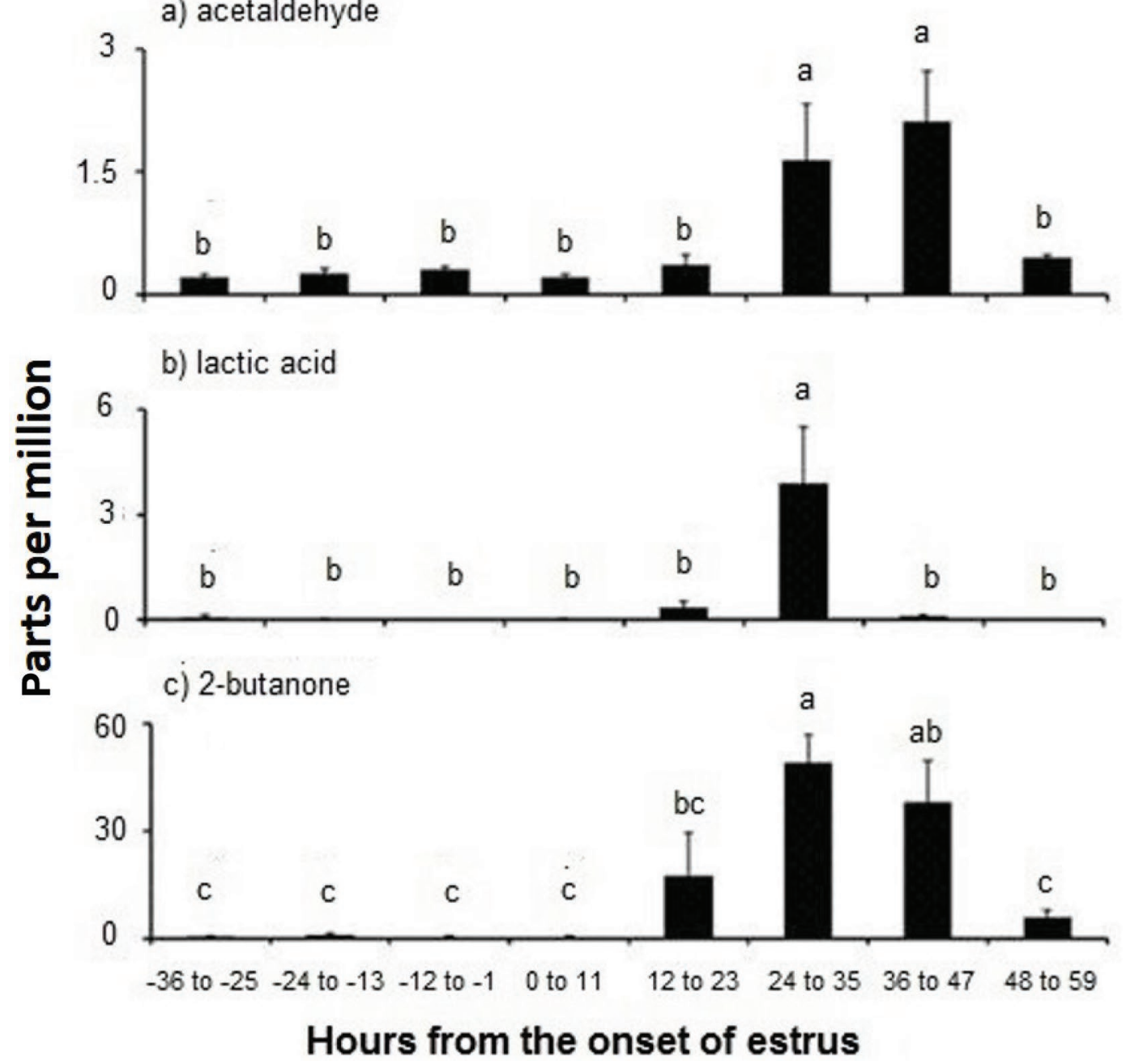

Figure 6. Mean $( \pm \mathrm{SEM})$ concentration (ppm) of (a) acetaldehyde, (b) lactic acid, and (c) 2-butanone, in cervicovaginal mucus of beef heifers $(\mathrm{n}=8)$ in experiment 1 measured by selected-ion flow-tube MS, presented in 12-h blocks of time relative to the onset of estrus (h 0$)$. Columns without a common letter $(\mathrm{a}-\mathrm{c})$ are different $(P<0.05)$.

acid $\beta$-oxidation (Walker and Mills, 2014); however, it has not been associated with estrous behavior to date despite being previously detected in fresh bovine milk (Weidong et al., 1997).

The second compound, 2-methyl-2 pentanone, is considered to be an oxygenated hydrocarbon lipid molecule. Its presence has been described in human feces (Garner et al., 2007) as well as in lactating cow open stall areas and a dairy slurry waste lagoon (Filipy et al., 2006). However, to date, its profile has not been associated with reproductive physiology.

Lactic acid was detected in significant quantities in bovine cervicovaginal mucus only about the time of ovulation. This is in agreement with the studies of human vaginal secretions that reported elevation of lactic acid concentrations near the time of ovulation (Preti and Huggins, 1975). Glycogen in the exfoliated cells of the human vagina are a rich substrate for bacterial flora (e.g., Lactobacillus acidophilus), which breaks glycogen down into lactic acid and lowers the vaginal pH (Juárez Tomás et al., 2003). Lactic acid was also detected in the oviduct fluid of ewes, but concentrations did not vary significantly across different stages of the estrous cycle (Perkins and Goode, 1966). Interestingly, a similar pattern to lactic acid was presented by ethanol and 2-butanol. These 2 alcohols are also produced from sugars by Lactobacillus brevis, commensal bacteria that can inhabit the vagina and gastrointestinal tract (Ghiaci et al., 2014). Also, the elevated concentrations of acetaldehyde were detected in bovine cervicovaginal mucus about the time of ovulation. This is in contrast to previous studies in which blood acetaldehyde levels were highest just before or at the time of estrus (Klemm et al., 1994). 


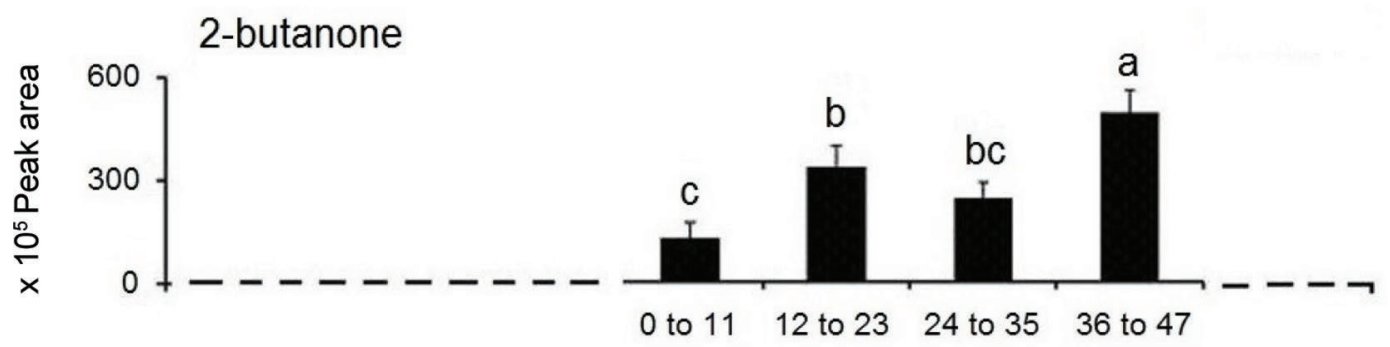

Hours from the onset of estrus

Figure 7. Mean $( \pm$ SEM $)$ relative abundance $\left(\times 10^{5}\right.$ peak area $)$ of 2-butanone in experiment $2(\mathrm{n}=15$ animals $)$, presented in 12 -h blocks of time relative to the onset of estrus (h 0). Broken axes (- - ) represent times when samples were not collected. Columns without a common letter $(\mathrm{a}-\mathrm{c})$ are different $(P<0.05)$.

The most abundant VOC detected in our study was 2-butanone, which presented a very clear profile with low or undetectable concentrations before the onset of estrus rising significantly after the onset of estrus. Its presence was measured using both GC-MS and SIFTMS in experiment 1 and further confirmed in experiment 2 in an independent group of heifers. 2-Butanone is a frequently identified VOC and, along with other compounds identified in this study, is one of the most abundant VOC in bovine milk (Hougaard et al., 2011). 2-Butanone was also identified in the urine and secretions of temporal glands of male African elephants and has been associated with musth, a periodic condition in bull elephants characterized by highly aggressive behavior accompanied by a large rise in reproductive hormones (Rasmussen and Wittemyer, 2002). 2-Butanone has been reported to be the most abundant VOC present in pre-estrus urine and estrus vaginal mucus in estrus-synchronized cows (Le Danvic et al., 2015). Our data are consistent with and extend these observations, providing a greater level of detail of the timing of the rise in 2-butanone. Interestingly, exposure of bulls to a cocktail of VOC including 2-butanone lowered their mounting reaction and ejaculation times compared with control bulls (Le Danvic et al., 2015). Similarly, it has been reported that acetic acid, 2-butanone, and oleic acid are effective for better sexual preparation of Zebu bulls and total sperm output per ejaculation (Mondal et al., 2019). Furthermore, Ramachandran et al. (2020) reported that butanoic acid, from which 2-butanol and 2 -butanone are derived by oxidation, was specific to both estrous urine and cervical mucus in Bos indicus cows. Thus, the presence of 2-butanone in various sample matrices, and its elevated pattern of expression during estrus, leads us to conclude that it is likely to be an important pheromone component signaling estrus in cattle.
In seeking to identify a marker that could be used to determine the time for $\mathrm{AI}$ in heifers, it may be best to develop a test that relies on a mixture of compounds, rather than an individual VOC, as has previously been addressed in bovine milk (Weidong et al., 1997) and urine samples (Manzoli et al., 2019). It should also be acknowledged that there may be other compounds, beyond the threshold of detection of the methods used in this study, that signal estrus (Stern and McClintock, 1998).

\section{CONCLUSIONS}

The present study used 2 mass spectral methods and characterized the changes in 49 VOC (47 compounds detected by GC-MS and 2 compounds quantified with SIFT-MS) in cervicovaginal mucus of heifers around the time of estrus and ovulation. Our study has led to the identification of 9 VOC in bovine cervicovaginal mucus the concentrations of which vary significantly around the onset of estrus (with 2-butanone showing the greatest abundance). The findings have undoubtedly greater relevance for dairy cows than beef cows given the much more widespread use of AI in the former. Interestingly, 2-butanone is detectable in milk (Toso et al., 2002; Villeneuve et al., 2013), which would be an easier matrix with which to work in lactating dairy cows. All VOC peak between 24 and $47 \mathrm{~h}$ after the onset of estrus. Only 2 VOC, 2-pentanone and 4-methyl-2-pentanone, showed a significant increase at the onset of estrus, indicating that they could potentially be used as biomarkers of estrus. We show that the pheromone signal for estrus in cervicovaginal mucus is complex, with the concentrations of different VOC exhibiting slightly different time courses of secretion that generally rise very close to the onset of estrus and then peak at about the time of ovulation. Further research is needed to confirm 
these results in independent larger groups of animals, which may lead to the development of new sensor devices that can reliably detect estrus and ovulation.

\section{ACKNOWLEDGMENTS}

Authors thank Science Foundation Ireland (Dublin, Ireland) for funding this work under grant no. 07/SRC/ B1156. The authors declare that they have no conflict of interest.

\section{REFERENCES}

Abuelnnor, N. A., P. R. H. Jones, N. M. Ratclife, B. D. Lacy Costello, and P. T. N. Spencer-Phillips. 2010. Investigation of the semiochemicals of confused flour beetle Tribolium confusum Jaquelinduval and grain weevil Sitophilus granaries (L.) in stored wheat grain and flour. 10th International Working Conference on Stored Product Protection. Julius Kühn-Institute, Berlin, Germany.

Bombardelli, G. D., H. F. Soares, and R. C. Chebel. 2016. Time of insemination relative to reaching activity threshold is associated with pregnancy risk when using sex-sorted semen for lactating Jersey cows. Theriogenology 85:533-539. https://doi.org/10.1016/ j.theriogenology.2015.09.042.

Burnett, T. A., L. Polsky, M. Kaur, and R. L. A. Cerri. 2018. Effect of estrous expression on timing and failure of ovulation of Holstein dairy cows using automated activity monitors. J. Dairy Sci. 101:11310-11320. https://doi.org/10.3168/jds.2018-15151.

Cabrera, V. E. 2014. Economics of fertility in high-yielding dairy cows on confined TMR systems. Animal 8:211-221. https://doi.org/10 $.1017 /$ S1751731114000512.

Carvalho, P. D., V. G. Santos, J. O. Giordano, M. C. Wiltbank, and P. M. Fricke. 2018. Development of fertility programs to achieve high 21-day pregnancy rates in high-producing dairy cows. Theriogenology 114:165-172. https://doi.org/10.1016/j.theriogenology .2018.03.037.

Cooke, D. J., M. A. Crowe, and J. F. Roche. 1997. Circulating FSH isoform patterns during recurrent increases in FSH throughout the oestrous cycle of heifers. J. Reprod. Fertil. 110:339-345. https:// doi.org/10.1530/jrf.0.1100339.

Dehnhard, M., and R. Claus. 1988. Reliability criteria of a bioassay using rats trained to detect estrus-specific odor in cow urine. Theriogenology 30:1127-1138. https://doi.org/10.1016/0093 -691X(88)90288-9.

Diskin, M. G. 2018. Semen handling, time of insemination and insemination technique in cattle. Animal 12(s1):75-84. https://doi.org/ 10.1017/S1751731118000952.

Dobson, H., J. Williams, J. E. Routly, D. N. Jones, J. Cameron, A. Holman-Coates, and R. F. Smith. 2018. Short communication: Chronology of different sexual behaviors and motion activity during estrus in dairy cows. J. Dairy Sci. 101:8291-8295. https://doi .org/10.3168/jds.2017-14341.

Filipy, J., B. Rumburg, G. Mount, H. Westberg, and B. Lamb. 2006. Identification and quantification of volatile organic compounds from a dairy. Atmos. Environ. 40:1480-1494. https://doi.org/10 .1016/j.atmosenv.2005.10.048.

Fischer-Tenhagen, C., D. Johnen, C. Le Danvic, J. Gatien, P. Salvetti, B. A. Tenhagen, and W. Heuwieser. 2015. Validation of bovine oestrous-specific synthetic molecules with trained scent dogs. Similarities between natural and synthetic oestrous smell. Reprod. Domest. Anim. 50:7-12. https://doi.org/10.1111/rda.12440.

Forde, N., F. Carter, T. Fair, M. A. Crowe, A. C. O. Evans, T. E. Spencer, F. W. Bazer, R. McBride, M. P. Boland, P. O'Gaora, P. Lonergan, and J. F. Roche. 2009. Progesterone-regulated changes in endometrial gene expression contribute to advanced conceptus development in cattle. Biol. Reprod. 81:784-794. https://doi.org/ 10.1095/biolreprod.108.074336.
Fricke, P.M., P.D. Carvalho, J.O. Giordano, A. Valenza, G. Lopes, and M.C. Amundson. 2014. Expression and detection of estrus in dairy cows: The role of new technologies. Animal 8:134-143. https://doi .org/10.1017/S1751731114000299.

Garner, C. E., S. Smith, B. Lacy Costello, P. White, R. Spencer, C. S. J. Probert, and N. M. Ratcliffe. 2007. Volatile organic compounds from feces and their potential for diagnosis of gastrointestinal disease. FASEB J. 21:1675-1688. https://doi.org/10.1096/fj .06-6927com.

Ghiaci, P., F. Lameiras, J. Norbeck, and C. Larsson. 2014. Production of 2-butanol through meso-2, 3-butanediol consumption in lactic acid bacteria. FEMS Microbiol. Lett. 360:70-75. https://doi.org/ 10.1111/1574-6968.12590.

Hawk, H. W., H. H. Conley, and C. A. Kiddy. 1984. Estrus-related odors in milk detected by trained dogs. J. Dairy Sci. 67:392-397. https://doi.org/10.3168/jds.S0022-0302(84)81314-4.

Hougaard, A. B., J. S. Vestergaard, C. Varming, W. L. P. Bredie, and R. H. Ipsen. 2011. Composition of volatile compounds in bovine milk heat treated by instant infusion pasteurisation and their correlation to sensory analysis. Int. J. Dairy Technol. 64:34-44. https: //doi.org/10.1111/j.1471-0307.2010.00641.x.

Juárez Tomás, M. S., V. S. Ocaña, B. Wiese, and M. E. Nader-Macías. 2003. Growth and lactic acid production by vaginal Lactobacillus acidophilus CRL 1259, and inhibition of uropathogenic Escherichia coli. J. Med. Microbiol. 52:1117-1124. https://doi.org/10.1099/ jmm.0.05155-0.

Kiddy, C. A., D. S. Mitchell, D. J. Bolt, and H. W. Hawk. 1978. Detection of estrus-related odors in cows by trained dogs. Biol. Reprod. 19:389-395. https://doi.org/10.1095/biolreprod19.2.389.

Kiddy, C. A., D. S. Mitchell, and H. W. Hawk. 1984. Estrus-related odors in body fluids of dairy cows. J. Dairy Sci. 67:388-391. https: //doi.org/10.3168/jds.S0022-0302(84)81313-2.

Klemm, W. R., G. F. Rivard, and B. A. Clement. 1994. Blood acetaldehyde fluctuates markedly during bovine estrous cycle. Anim. Reprod. Sci. 35:9-26. https://doi.org/10.1016/0378-4320(94)90003-5.

Larson, L. L., and P. J. H. Ball. 1992. Regulation of estrous cycles in dairy cattle: A review. Theriogenology 38:255-267. https://doi .org/10.1016/0093-691X(92)90234-I.

Le Danvic, C., O. Gérard, E. Sellem, C. Ponsart, P. Chemineau, P. Humblot, and P. Nagnan-Le Meillour. 2015. Enhancing bull sexual behavior using estrus-specific molecules identified in cow urine. Theriogenology 83:1381-1388. https://doi.org/10.1016/j .theriogenology.2015.02.004.

Louhimies, S. 2002. Directive 86/609/EEC on the protection of animals used for experimental and other scientific purposes. Altern. Lab. Anim. 30(Suppl 2):217-219. https://www.doi.org/10.1177/ $026119290203002 \mathrm{~S} 36$.

Manzoli, A., C. Steffens, R. T. Paschoalin, A. M. Graboski, H. De Mello Brandão, B. C. de Carvalho, J. L. Bellini, and P. S. de Paula Herrmann Jr.. 2019. Volatile compounds monitoring as indicative of female cattle fertile period using electronic nose. Sens. Actuators B Chem. 282:609-616. https://doi.org/10.1016/j.snb.2018.11 .109 .

Mondal, S., M. Bhakat, A. Singh, T. K. Mohanty, M. Abdullah, S. K. Yadav, and R. Kumar. 2019. Effect of cattle-specific estrus molecules on libido and semen production of zebu bulls under tropical climate. Trop. Anim. Health Prod. 51:1823-1827. https://doi.org/ 10.1007/s11250-019-01880-8.

Mozūraitis, R., J. Kutra, A.-K. Borg-Karlson, and V. Būda. 2017. Dynamics of putative sex pheromone components during heat periods in estrus-induced cows. J. Dairy Sci. 100:7686-7695. https://doi .org/10.3168/jds.2016-12376.

Nebel, R. 2018. Time of insemination relative to onset of activity threshold of cow manager ${ }^{\circledR}$ is associated with pregnancy risk when using gender selected ${ }^{\mathrm{TM}}$ semen for Jersey cattle. J. Dairy Vet. Sci. 5:1-3. https://doi.org/10.19080/JDVS.2018.05.555653.

Nordéus, K., B. Webster, L. Söderquist, R. Bàge, and R. Glinwood. 2014. Cycle-characteristic odour of cow urine can be detected by the female face fly (Musca autumnalis). Reprod. Domest. Anim. 49:903-908. https://doi.org/10.1111/rda.12393. 
Perkins, J. L., and L. Goode. 1966. Effects of stage of the estrous cycle and exogenous hormones upon the volume and composition of oviduct fluid in ewes. J. Anim. Sci. 25:465-471. https://doi.org/ 10.2527 /jas1966.252465x.

Preti, G., and G. R. Huggins. 1975. Cyclical changes in volatile acidic metabolites of human vaginal secretions and their relation to ovulation. J. Chem. Ecol. 1:361-376. https://doi.org/10.1007/ BF00988838.

Ramachandran, R., A. Vinothkumar, D. Sankarganesh, U. Suriyakalaa, V. S. Aathmanathan, S. Kamalakkannan, V. Nithya, J. Angayarkanni, G. Archunan, M. A. Akbarsha, and S. Achiraman. 2020. Detection of estrous biomarkers in the body exudates of Kangayam cattle (Bos indicus) from interplay of hormones and behavioral expressions. Domest. Anim. Endocrinol. 72:106392. https: //doi.org/10.1016/j.domaniend.2019.106392.

Randi, F., M. McDonald, P. Duffy, A. K. Kelly, and P. Lonergan. 2018. The relationship between external auditory canal temperature and onset of estrus and ovulation in beef heifers. Theriogenology 110:175-181. https://doi.org/10.1016/j.theriogenology.2018.01 .001 .

Rasmussen, L. E. L., and G. Wittemyer. 2002. Chemosignalling of musth by individual wild African elephants (Loxodonta africana): Implications for conservation and management. Proc. Biol. Sci. 269:853-860. https://doi.org/10.1098/rspb.2001.1933.

Roelofs, J., F. López-Gatius, R. H. F. Hunter, F. J. C. M. van Eerdenburg, and C. Hanzen. 2010. When is a cow in estrus? Clinical and practical aspects. Theriogenology 74:327-344. https://doi.org/10 $.1016 /$ j.theriogenology.2010.02.016.

Sankar, R., and G. Archunan. 2004. Flehmen response in bull: role of vaginal mucus and other body fluids of bovine with special reference to estrus. Behav. Processes 67:81-86. https://doi.org/10 .1016/j.beproc.2004.02.007.

Sankar, R., and G. Archunan. 2005. Discrimination of bovine estrusrelated odors by mice. J. Ethol. 23:147-151. https://doi.org/10 .1007/s10164-004-0140-4.

Shalloo, L., A. Cromie, and N. McHugh. 2014. Effect of fertility on the economics of pasture-based dairy systems. Animal 8:222-231. https://doi.org/10.1017/S1751731114000615.

Stern, K., and M. K. McClintock. 1998. Regulation of ovulation by human pheromones. Nature 392:177-179. https://doi.org/10.1038/ 32408 .

Toso, B., G. Procida, and B. Stefanon. 2002. Determination of volatile compounds in cows' milk using headspace GC-MS. J. Dairy Res. 69:569-577. https://doi.org/10.1017/S0022029902005782.
Valenza, A., J. O. Giordano, G. Lopes Jr., L. Vincenti, M. C. Amundson, and P. M. Fricke. 2012. Assessment of an accelerometer system for detection of estrus and treatment with gonadotropin-releasing hormone at the time of insemination in lactating dairy cows. J. Dairy Sci. 95:7115-7127. https://doi.org/10.3168/jds.2012-5639.

Veronese, A., O. Marques, R. Moreira, A. L. Belli, T. R. Bilby, and R. C. Chebel. 2019. Estrous characteristics and reproductive outcomes of Holstein heifers treated with 2 prostaglandin formulations and detected in estrus by an automated estrous detection or mounting device. J. Dairy Sci. 102:6649-6659. https://doi.org/10 $.3168 /$ jds.2018-15957.

Villeneuve, M.-P., Y. Lebeuf, R. Gervais, G. F. Tremblay, J. C. Vuillemard, J. Fortin, and P. Y. Chouinard. 2013. Milk volatile organic compounds and fatty acid profile in cows fed timothy as hay, pasture, or silage. J. Dairy Sci. 96:7181-7194. https://doi.org/10 .3168/jds.2013-6785.

Walker, V., and G. A. Mills. 2014. 2-Pentanone production from hexanoic acid by Penicillium roqueforti from blue cheese: Is this the pathway used in humans? ScientificWorldJournal 2014:215783. https://doi.org/10.1155/2014/215783.

Walker, W. L., R. L. Nebel, and M. L. McGilliard. 1996. Time of ovulation relative to mounting activity in dairy cattle. J. Dairy Sci. 79:1555-1561. https://doi.org/10.3168/jds.S0022-0302(96)76517 -7 .

Weidong, M. A., B. A. Clement, and W. R. Klemm. 1997. Volatile compounds of bovine milk as related to the stage of the estrous cycle. J. Dairy Sci. 80:3227-3233. https://doi.org/10.3168/jds.S0022 -0302(97)76296-9.

Zellner, B. D., C. Bicchi, P. Dugo, P. Rubiolo, G. Dugo, and L. Mondello. 2008. Linear retention indices in gas chromatographic analysis: A review. Flavour Fragrance J. 23:297-314. https://doi.org/10 $.1002 /$ ffj. 1887.

\section{ORCIDS}

Katarzyna Pluta @ https://orcid.org/0000-0001-7585-5140

Peter R. H. Jones @ https://orcid.org/0000-0002-3497-9304

Natalia Drabińska (๑ https://orcid.org/0000-0001-5324-5982

Stephen D. Carrington (1) https://orcid.org/0000-0002-8051-5906

Patrick Lonergan ( https://orcid.org/0000-0001-5598-5044

Alexander C. O. Evans @ https://orcid.org/0000-0002-6344-6224 